17 Besag FMC. Difficult-to-treat childhood epilepsies. In Reynolds $\mathrm{EH}$, ed. Lamotrigine - a new advance in the treatment of epilepsy. London: Royal Society of Medicine treatment of epilepsy. Lond

18 Snead OC, Hosey LC. Exacerbation of seizures in children by carbamazepine. $N$ Engl $\mathcal{M}$ Med 1985; 313: 916-21.

19 Shinnar S, Berg AT, Moshé SL, et al. Discontinuing antiepileptic drugs in children with epilepsy: a prospectiv study. Ann Neurol 1994; 35: 534-45.

20 Emerson E, D'Souza BJ, Vining EP, Holden KR, Mellits ED, Freeman JM. Stopping medication in children with epilepsy. Predictors of outcome. N Engl f Med 1981; 304 1125-9.

21 Camfield C, Camfield P, Gordon K, Smith P, Dooley J. Outcome of childhood epilepsy. A population-based study with a simple predictive scoring system for those treated with medication. $\mathcal{F}$ Pediatr 1993 ; 122: 861-8.

22 Holmes GL. Surgery for intractable seizures in infancy and early childhood. Neurology 1993; 43 (suppl 5): S28-37.

23 Joint Working Group of the Royal College of Physicians and the British Paediatric Association. Guidelines for the

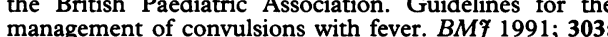
managem

24 Camfield PR, Camfield CS. Febrile seizures. In: Ross EM, Woody RC, eds. Epilepsy. Baillière's clinical paediatrics. International practice and research. Vol 2, No 3. London: Baillière Tindall, 1994: 547-59.

25 Cavazzuti GB, Capella L, Nalin A. Longitudinal study of epileptiform EEG patterns in normal children. Epilepsia 1980; 21: 43-55.

26 Lerman P, Kivity S. Focal epileptic EEG discharges in children not suffering from clinical epilepsy. In: Degan $\mathbf{R}$, Dreifuss FE, eds. Benign localized and generalized epilepsies of early childhood. Amsterdam, London: Elsevier, 1992. 99-103.

27 Yang PJ, Berger PE, Cohen ME, Duffner PK. Computed tomography and childhood seizure disorders. Neurology 1979; 29: 1084-8.

28 Gordon N. Computed tomography in childhood epilepsy.
Arch Dis Child 1988; 63: 1114.

29 Barnes PD. Imaging of the central nervous system in pediatrics and adolescence. Pediatr Clin North Am 1992; 39: 743-76.

30 Anonymous. Magnetic resonance imaging in epilepsy [Editorial]. Lancet 1992; 340: 343-4

31 Kuzniecky R, Andermann F, Guerrini R, and the Congenital Bilateral Perisylvian Syndrome (CBPS) Multicenter Collaborative Study. Congenital bilatera perisylvian syndrome: study of 31 patients. Lancet 1993; 341: $608-12$.

32 Kuzniecky R. Magnetic resonance imaging in developmental disorders of the cerebral cortex. Epilepsia 1994; 35 (suppl 6): S44-56

33 Wyllie E, Lüders $\mathbf{H}$. Complex partial seizures in children: clinical manifestations and identification of surgical candidates. Cleve Clin F Med 1989; 56 (suppl (pediatric epileptology) part I): S43-52.

34 Cross JH, Jackson GD, Neville BGR, et al. Early detection of abnormalities in partial epilepsy using magnetic resonance. Arch Dis Child 1993; 69: 104-9.

35 Anonymous. SPECT and PET in epilepsy [Editorial]. Lancet 19891 333: 135-7.

36 Jackson GD. New techniques in magnetic resonance and epilepsy. Epilepsia 1994; 35 (suppl 6): S2-13.

37 Gibbs J, Appleton RE, Carty H, Beirne M, Acomb BA Focal electroencephalographic abnormalities and computerised tomographic findings in children with seizures. $\mathcal{F}$ Neurol Neursurg Psychiatry 1993; 56: 369-71.

38 Lee TKY, Nakusa Y, Jeffree MA, Molyneaux AJ, Adam CBT. Indolent glioma: a cause of epilepsy. Arch Dis Child 1989; 64: 1666-71.

39 Riikonen R, Simell $O$. Tuberose sclerosis and infantile spasms. Dev Med Child Neurol 1990; 32: 203-9.

40 Hull D. A question of negligence. Current Paediatrics 1993; 3: 52-5.

41 Aoki N. Chronic subdural haematoma in infancy: clinical analysis of 30 cases in the CT era. 7 Neurosurg 1990; 73: 201-5.

\title{
The place of the EEG and imaging in the management of seizures
}

Child Development Centre, Addenbrooke's Hospital, Hills Road, Cambridge CB2 $20 Q$

Correspondence to: Dr Verity.
C M Verity

'Most diagnostic investigations are open to abuse, but none more so than the EEG'. (Binnie 1994. ${ }^{1}$ )

'There is considerable debate in the literature about whether all patients with seizures require CT scans.' (Holmes 1989.2)

This paper discusses the choice of appropriate investigations for children with seizures and takes the form of a series of questions for which answers are suggested. The word seizure is used rather than fit and the term febrile convulsion rather than febrile seizure. Epilepsy is defined as recurrent (more than one) afebrile seizures.

\section{General considerations}

WHAT TYPES OF SEIZURE OCCUR IN CHILDHOOD AND WHY DOES IT MATTER? When considering a general approach to children with seizures it helps to know the frequency of seizure types in the population. The table shows some of the findings of the Child Health and Education Study, which followed up a national cohort of children for the first 10 years of life. ${ }^{34}$ Some of the important observations were as follows: febrile convulsions were relatively common - they affected $2 \cdot 7 \%$ of children. The majority were simple febrile convulsions, but $22 \%$ were complex (that is longer than 15 minutes' duration, focal or multiple during one episode of fever). Afebrile seizures were much less common - about $0.4 \%$ of children in the study had epilepsy. The commonest afebrile seizure type was tonicclonic, but complex partial seizures were the next and classical childhood absence seizures ('petit mal') were the least common of all (just one child in the cohort).

The cause of seizures and the prognosis varies with the seizure type. When considering appropriate investigations for the individual child it makes sense to consider which seizure types occur most commonly - children with 'blank spells' are more likely to be having complex partial seizures or atypical absences than true 'petit mal' (see the table).

\section{WHEN SHOULD INVESTIGATIONS BE}

PERFORMED?

Not too soon. The most important step is to obtain a good history. The parents may be able to record attacks at home using their own video. ${ }^{5}$ The diagnosis of epilepsy is clinical and should not be made without 'incontrovertible clinical evidence'. ${ }^{6}$ Such evidence is usually provided by the patient's description and by 
observation, not by investigation. The clinician should have decided whether or not seizures have occurred and should have formed an opinion about the probable seizure type before organising confirmatory investigations.

\section{WHAT ARE THE PRACTICAL CONSIDERATIONS} WHEN CHOOSING INVESTIGATIONS?

\section{(A) $E E G$}

This is the basic tool for the investigation of children with seizures. However, with the exception of absence seizures, it is rare to record a seizure during a routine electroencephalogram (EEG) and a normal recording does not exclude the possibility that seizures are occurring at another time. If the trace is recorded and reported by staff experienced in paediatric work, one of the strengths of the standard EEG is that the abnormalities are well recognised and the findings are reliable. When the recording is less controlled the risk of artefact is greater, and this should be borne in mind when considering some types of prolonged monitoring. One way of improving the diagnostic yield, particularly in children with suspected temporal lobe onset seizures, is to perform a sleep EEG and there is a good argument for making this part of the initial investigation of all patients with suspected epilepsy. ${ }^{1}$

\section{(B) Imaging}

Computed tomography exposes the child to $x$ rays and because of bony interference the temporal lobes and the contents of the posterior fossa are not well visualised. This is not a problem with magnetic resonance imaging (MRI). In Aicardi's opinion MRI is far superior to computed tomography except in the recognition of calcification. ${ }^{7}$ MRI is not as widely available as computed tomography and it is more difficult to obtain MRI scans on young children, nevertheless good quality MRI scans can be obtained in the majority of children using sedation rather than general anaesthesia.

\begin{tabular}{lc} 
Children with febrile convulsions and afebrile seizures in the \\
first 10 years of life. Findings of the Child Health and \\
Education Study \\
\hline \\
\hline All cohort children for whom information \\
available & 14676 \\
Children with febrile convulsions & 398 \\
Total No in cohort & $2 \cdot 7 \%$ \\
Incidence & $311(78 \%)$ \\
Type of febrile convulsion & $87(22 \%)$ \\
First attack simple & \\
First attack complex & $63 \star$ \\
Children with epilepsy (recurrent afebrile seizures) & $0 \cdot 4 \%$ \\
Total No in cohort & \\
Incidence & $84 \star$ \\
Children with one or more afebrile seizures & \\
Total No in cohort & 42 \\
Type of afebrile seizure & 25 \\
Tonic-clonic & 9 \\
Complex partial & 3 \\
Mixed & 2 \\
Infantile spasms & 1 \\
Atypical absence & 1 \\
Absence ('petit mal') & 1 \\
Myoclonic &
\end{tabular}

* Twenty one children had a single afebrile seizure in the first 10 years, therefore $84-21=63$ had recurrent afebrile seizures,
that is, epilepsy.

\section{Investigation of febrile convulsions}

What investigations have been recommended by other authors?

There has been considerable diversity of opinion. Rosman recommended after a (hypothetical) brief initial febrile seizure in a 4 year old boy that there should be waking and sleep EEGs, that nasopharyngeal and sphenoidal leads should be considered to look for a temporal lobe focus, that a computed tomogram should be performed, and that the child should be followed with serial EEGs - a very rigorous approach. ${ }^{8}$ In 1991 Millichap and Colliver published the results of a questionnaire survey of the members of the Child Neurology Society of North America. ${ }^{9}$ Of those who responded $45 \%$ reported that they used the EEG to determine the need for long term anticonvulsant treatment. In contrast the members of a working group at the Royal College of Physicians in London concluded that 'no investigations are routinely necessary in all children after a febrile convulsion'. ${ }^{10}$

Why consider an EEG or a scan after a child has had a febrile convulsion?

The pressure to investigate has been generated at least partly by concern that febrile convulsions may cause brain damage. Much of the evidence for this has come from studies of adults with refractory temporal lobe epilepsy attending specialised clinics. Some of these adult patients have 'mesial temporal sclerosis' (gliosis and neuronal cell loss in the region of the hippocampus) which has been demonstrated in resected temporal lobes of patients after surgery for epilepsy ${ }^{11}$ and also by using high resolution volumetric MRI. ${ }^{12}$ A strong relationship between hippocampal sclerosis and a history of childhood febrile convulsions has been demonstrated and it has been suggested that the febrile convulsions cause the sclerosis. ${ }^{11}$ Kuks et al commented that if childhood febrile convulsions cause some cases of hippocampal sclerosis this cannot be the only mechanism as $64 \%$ of their patients with hippocampal volume loss gave no history of childhood febrile convulsions. ${ }^{12}$

It is important to remember the findings of population based studies when considering this question. Large cohort studies on both sides of the Atlantic show that there is an increased risk of epilepsy after febrile convulsions, but for the majority of the children, those that have simple febrile convulsions, the increased risk is relatively small. The risk is greater in the minority that have complex febrile convulsions, particularly after those with focal features, ${ }^{3} 1314$ but the evidence from the Child Health and Education Study cohort is that prolonged febrile convulsions are rarely followed by epilepsy of the temporal lobe type. ${ }^{3}$ Indeed the majority of children with febrile convulsions have only one febrile convulsion in their lives. ${ }^{15}$ This raises the question: is there ever any indication for performing an EEG or a scan in these children? 


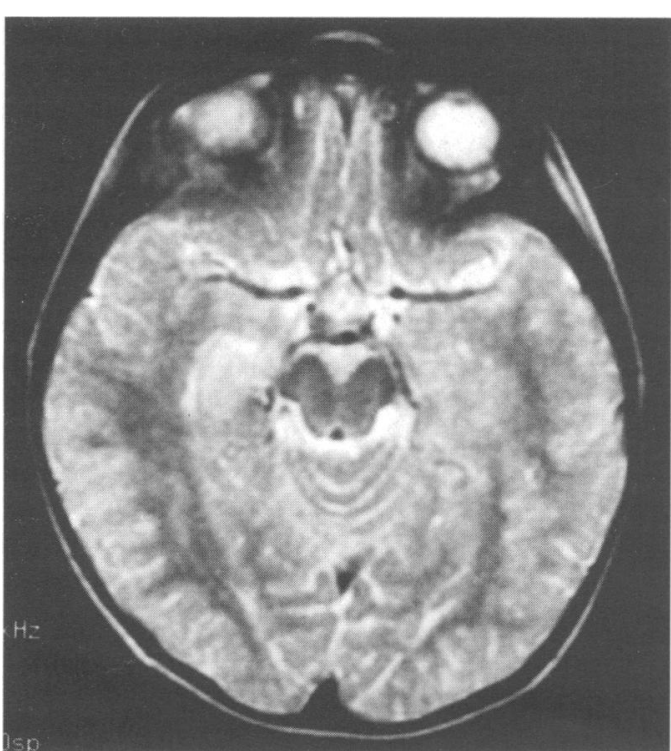

Figure 1 MRI scan of a young child, performed soon after a prolonged focal afebrile seizure. There was a history of a single previous febrile convulsion, but of no other seizures. The appearances suggest that this child has mesial temporal sclerosis on the right (the left side of the scan). A computed tomogram would probably not have shown this abnormality.

Does an EEG predict which children with febrile convulsions will develop epilepsy?

In recent reviews the conclusion has been that EEGs are not helpful in assessing the prognosis of children who have had febrile convulsions. ${ }^{171617}$

\section{Is scanning ever indicated in children who have} had febrile convulsions?

It could be argued that a scan should be performed after prolonged or focal febrile convulsions because of the concern that these may be associated with mesial temporal sclerosis (see above). To detect evidence of temporal lobe damage an MRI scan would have to be obtained (see fig 1). Would the scan findings influence management? There are two possibilities:

(1) Recommend the use of rectal diazepam to shorten subsequent febrile convulsions. It does not seem necessary to perform a scan before making this decision - it can be made on the basis of the history. (While it is accepted practice to provide rectal diazepam for carers to use during a subsequent febrile convulsion, it is reassuring that there is evidence ${ }^{318}$ that febrile convulsions do not become progressively more severe with each attack.)

(2) Prescribe regular anticonvulsants. The Royal College of Physicians/British Paediatric Association working group concluded that 'there is no evidence that in the minority of children who later develop epilepsy the prophylactic use of anticonvulsant drugs would have prevented it'. ${ }^{10}$

The finding of an abnormality on the MRI scan could help to make a decision about the need for anticonvulsant treatment after a child presents with a prolonged or focal febrile convulsion. In the light of the outcome data discussed above, the finding of mesial temporal sclerosis in these circumstances probably indicates that there is increased risk of later afebrile seizures. At present, however, the decision remains difficult because there is no clear evidence that the early use of prophylactic anticonvulsant treatment reduces the risk.

A child with a developmental or neurological problem may first come to medical attention because of a febrile convulsion, so there will be occasions when an abnormal history or examination indicates the need for a scan. This is in the minority of children with febrile convulsions.

\section{Investigation of afebrile seizures}

(1) THE FIRST AFEBRILE SEIZURE

$E E G$ - all or none?

'Because EEGs are noninvasive, benign and relatively inexpensive it is reasonable to obtain at least one for a patient with a seizure or suspected seizure'. (Holmes 1988. ${ }^{19)}$

'There is no justification for recording an EEG after an initial seizure in adults'. (Hopkins et al $1988 .^{20}$ )

Holmes (see above) advocated EEGs for all. He recommended that the trace should be obtained as soon as possible because focal slowing may indicate focal disease ${ }^{19} \mathrm{I}$ think that it is better to look for evidence of a focal abnormality in the history and/or the physical examination and investigate with a scan if indicated.

Hopkins et al found that an EEG in adults is of low or negligible value in predicting recurrence after an initial seizure. ${ }^{20}$ It may define seizure type, but the authors thought that this was of academic interest only, as most first seizures are not treated in current practice. Their conclusion was that there was no justification for recording the EEG after an initial seizure in adults. In contrast Van Donselaar et al found in adults that epileptic discharges were associated with an increased risk of recurrence and concluded that the decision to initiate or delay treatment should be based on EEG findings. ${ }^{21}$ They cited evidence that 'immediate' treatment of patients with epileptic discharges after the first seizure might prevent seizure intractability in some patients. The question is not resolved, which is why the Medical Research Council 'Multicentre Study of Early Epilepsy and Single Seizures' is currently being undertaken in the UK (further information from Professor Chadwick, Walton Hospital, Liverpool).

In my experience parents are not keen to give their children anticonvulsants. It is unlikely to become accepted clinical practice to prescribe these drugs after the first seizure until there is evidence that it improves outcome. I therefore agree with Hopkins et $a l^{20}$ that there is little practical value in recording an EEG after an initial seizure.

What are the indications for a scan after the first afebrile seizure?

Holmes recommended that all patients presenting with a first seizure should have a 

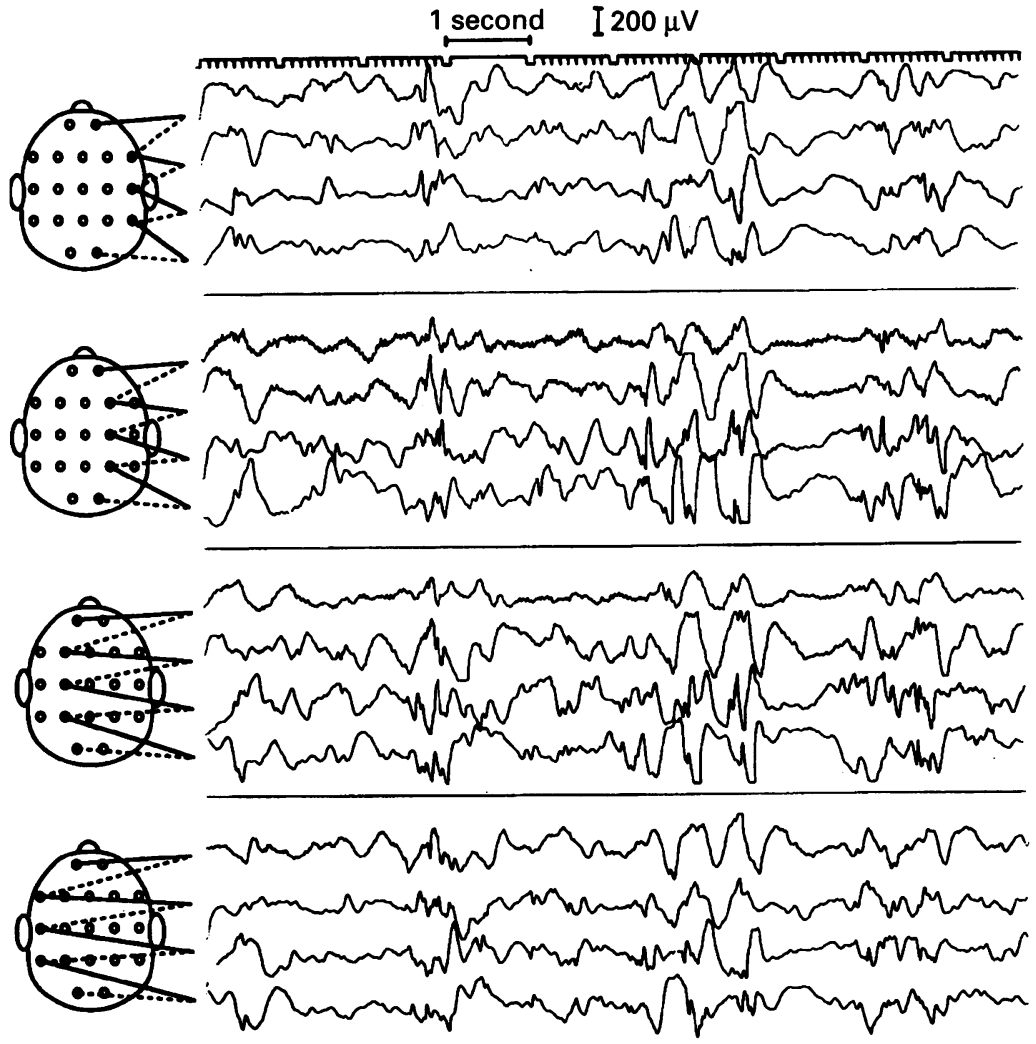

Figure 2 EEG of a child who presented in the first year of life with infantile spasms (recorded while awake). The pattern is that of hypsarrhythmia-high voltage slow waves, irregularly mixed with spikes and sharp waves that occur randomly. A periodic pattern is often observed. Hypsarrhythmia is the pattern that is typically seen in children with infantile spasms but even this well known association is not found in all cases.

computed tomogram (except for those with absence seizures or rolandic epilepsy who have normal results on neurological examination). ${ }^{19}$ However, in his review he quoted four studies of computed tomography in children with seizures which indicated that the computed tomography findings do not usually alter the clinical management.

Studies in adults have indicated that a scan is not indicated in all cases. Russo and Goldstein (on the basis of small numbers) concluded that computed tomography was not essential after a single seizure in adults aged 16 to 30 who have a normal neurological examination. ${ }^{22}$ Hopkins et al, partly on the basis of their research, adopted the practice of scanning an adult after a first seizure if the clinical onset of the seizure was clearly partial, or if there were focal neurological signs that were not clearly accounted for by known pre-existing neurological damage, such as cerebral palsy or embolus. ${ }^{20}$ Although based on studies in adults, these seem reasonable guidelines for the management of children after first afebrile seizures.

(2) RECURRENT AFEBRILE SEIZURES (EPILEPSY) The EEG - can it answer the following questions? It is really epilepsy? - Binnie's view is that the EEG is overused as an aid to the diagnosis of epilepsy, which in general it can only support and rarely exclude. 1 Goodin and Aminoff found that the presence of epileptiform features on the interictal EEG gave strong support when the diagnosis was clinically suspected, ${ }^{23}$ but that a normal record could not exclude the diagnosis. A single waking EEG demonstrates epileptiform activity in about $50 \%$ of adults with epilepsy (it is difficult to find these data for children). However, a sleep recording immediately provides a yield of about $80 \%$ and should be considered as part of the initial EEG investigation of all patients with suspected epilepsy. ${ }^{1}$

Prolonged monitoring may help by recording the EEG during an attack (see reviews by Binnie, ${ }^{1}$ Holmes, ${ }^{2}$ Stores, ${ }^{24}$ and Mizrahi $^{25}$ ). Telemetry allows the EEG to be monitored in hospital while behaviour is monitored by video recording. Split screen recording allows the EEG trace to be compared with the simultaneous video. The alternative is ambulatory monitoring of the EEG using a portable cassette recorder which frees the child to leave hospital, but behavioural documentation is then less reliable. Ambulatory monitoring is not as good as telemetry in detecting minor seizures, locating the site of onset of seizures, or deciding whether subtle events are epileptic. ${ }^{1}$ It is, however, preferred for investigating a known EEG abnormality, for example the frequency of absence seizures in class.

Holmes suggested that these were the indications for prolonged monitoring ${ }^{2}$ :

- When seizures are suspected and routine EEGs have been normal or equivocal

- In patients with suspected pseudoseizures

- Where an exact seizure count is needed

- In candidates for epilepsy surgery

Prolonged monitoring is not a substitute for careful clinical assessment. It should be used to answer a defined clinical question. There may be particular difficulties when it is used to investigate episodic abnormal behaviour because of the practical problems of obtaining a reliable recording and also because some types of seizure do not produce ictal EEG changes. ${ }^{1}$

What type of seizure or seizure syndrome is it? (1) The EEG becomes most useful when it is used for the classification of seizures. ${ }^{1}$ It can distinguish between generalised seizures, which apparently arise simultaneously in both hemispheres, and partial seizures, in which seizure onset is confined to a discrete region of cortex. The EEG is especially important in two clinical settings:

(A) In distinguishing between typical absence seizures (often associated with generalised spike-wave activity) and complex partial seizures (where there may be focal spike activity).

(B) In patients with tonic-clonic seizures without an aura it may differentiate between primary generalised seizures and those with a focal onset. It is when looking for a focal onset to seizures, particularly from the temporal lobe, that sleep EEGs may be particularly useful in childhood.

(2) By putting the particular seizure type in the context of the clinical setting it is possible to look for features of a particular seizure syndrome. For instance the EEG is essential for the evaluation of children with West's 
syndrome (see fig 2), the Lennox-Gastaut syndrome, childhood absence epilepsy, benign partial epilepsy with rolandic spikes, and juvenile myoclonic epilepsy.

Can the EEG help the management of problems with learning and behaviour in children with epilepsy? - Binnie et al have reported that subclinical discharges may be associated with disruption of learning ${ }^{26}$ and Stores has discussed the possible direct effects of seizure discharges on learning and behaviour. ${ }^{27}$ Comprehensive monitoring techniques can be used to quantify EEG epileptiform activity and thus can objectively assess the efficacy of anticonvulsants. ${ }^{25}$ It is not yet being suggested that we 'treat the EEG', but this technology might be useful for some children in the future.

Place of scanning in the investigation of epilepsy When are scans indicated? Bachman et al studied 98 children with chronic seizure disorders who were referred by their physicians for computed tomography (they were thus a group with relatively severe seizures). ${ }^{28}$ All of them had a computed tomogram with contrast. Structural abnormalities were found in $30 \%$ of the children. The most common abnormality was either focal or generalised atrophy. The only abnormalities which were potentially of therapeutic significance were two suspected tumours.

Holmes $^{19}$ reviewed the study of Bachman et $a l^{28}$ and three other studies of computed tomography in children with epilepsy. The frequency of an abnormality on the computed tomogram ranged from $30 \%$ to $40 \%$ (average $38 \%$ ). Abnormalities on the scan were more frequent in patients with partial seizures, abnormal neurological findings, focal paroxysmal discharges, or slowing on the EEG. However, these findings usually did not alter clinical management. Aicardi stated that computed tomograms were unlikely to reveal a focal lesion, let alone a tumour, in patients with primary generalised epilepsies. ${ }^{7}$ Chadwick thought that it might be best to scan patients whose epilepsy is unresponsive to drug treatment rather than all patients at presentation. ${ }^{6}$

I suggest the following guidelines, which are partly based on those jointly agreed by the British Paediatric Neurology Association and the Radiology Specialty Group of the British Paediatric Association, but which are my personal recommendations:

(1) Not every child with epilepsy needs a brain scan.

(2) A focal discharge (spike, sharp, or slow wave) on an EEG is not in itself an indication to perform a brain scan.

(3) Some children with epilepsy are more likely than others to have an underlying structural abnormality of the brain. In the following groups a scan seems to be indicated:

(a) Those who present with seizures in the first year of life.

(b) Those in whom the history or physical examination suggests that there is an abnormality of the central nervous system (in addition to the tendency to have seizures), for example those with partial seizures, a neurological deficit or a neurocutaneous syndrome.

(c) Those with evidence of development delay or regression.

(d) Those with seizures that are refractory to treatment.

These guidelines are not absolute - for instance it can be seen from the table that a large proportion of children have complex partial seizures. It is not my practice to perform a scan on all children with complex partial seizures unless there are abnormal neurological signs or the seizures are refractory to treatment. Other clinicians are likely to have a different approach.

What is the best type of scan? There seems no doubt that MRI is better than computed tomography for the investigation of children with epilepsy. ${ }^{7} \mathrm{MRI}$ is particularly indicated when imaging small tumours in the temporal lobe or close to bony structures. ${ }^{729} 30$ MRI may have problems - differentiation of tumours from inflammatory or dysplastic lesions may be difficult. ${ }^{7}$ When evaluating children for surgery, newer methods of scanning may improve the diagnostic yield functional scanning with position emission tomography (PET) and single photon emission tomography (SPECT) is now being used. ${ }^{29-33}$ In patients with refractory temporal lobe epilepsy these new techniques have been very sensitive in detecting the region of metabolic dysfunction corresponding to the EEG focus. ${ }^{29} 30$ Functional imaging has also identified metabolic disturbances associated with microscopic abnormalities of the brain where it had been thought that surgical treatment would not be possible. For instance Sankar and Chugani reported on the use of PET to detect 'nociferous' cortex in children with partial epilepsy starting in the neonatal or early infantile period and also in children with 'cryptogenic' infantile spasms. ${ }^{33}$ In both these groups resection of the abnormal tissue led to clinical improvement in seizure control and improved developmental progress. ${ }^{31-33}$ Functional imaging has also been used to study children with the Sturge-Weber syndrome, the Lennox-Gastaut syndrome $\mathrm{e}^{31-33}$ and the Landau-Kleffner syndrome. ${ }^{34}$

\section{Final advice - a personal view}

- What do the 'attacks' feel like and look like? Get the history first.

- Make a diagnosis and then consider tests they are not always needed.

- Most febrile convulsions do not require investigation with EEG or scan.

- Investigations are rarely required after the first afebrile seizure.

- When epilepsy needs treatment use the EEG to identify the seizure type (and syndrome). 'Blank spells' are more likely to be atypical absences or complex partial seizures than 'petit mal'. The EEG may be normal in children with temporal lobe seizures: try a sleep EEG next. 
- Prolonged EEG monitoring can be helpful in selected cases, but do not underestimate the value of the 'standard' EEG, particularly if a sleep study is performed.

- Not every child with epilepsy needs a brain scan. Consider a scan if the clinical findings suggest an underlying cause or seizures are refractory.

- MRI is usually better than computed tomography for investigating children with epilepsy.

Many thanks to Dr NM Antoun, consultant neuroradiologist, and to Dr SJ Boniface, consultant neurophysiologist, both of Addenbrooke's Hospital, for their advice and help with the figures.

1 Binnie CD. Neurophysiological investigation of epilepsy in children. In: Ross EM, Woody RC, eds. Epilepsy. Baillière's clinical paediatrics. Intermational practice and research. Vol 2 No 3. London: Baillière Tindall, 1994: 585-604.

2 Holmes GL. Electroencephalographic and neuroradiologic evaluation of children with epilepsy. Pediatr Clin North Am 1989; 36: 395-420.

3 Verity CM, Golding J. Risk of epilepsy after febrile convulsions: a national cohort study. $B M F$ 1991; 303: vulsions:

4 Verity CM, Ross EM, Golding J. Epilepsy in the first 10 years of life: findings of the child health and education study. BMF 1992; 305: 857-61.

5 Woody RC. Home videorecording of 'spells' in children. Pediatrics 1985; 76: 612-3.

6 Chadwick D. Epilepsy octet. Diagnosis of epilepsy. Lancet 1990; 336: 291-5.

7 Aicardi J. Epilepsy in children. 2nd Ed. New York: Raven Press, 1994.

8 Rosman NP. Febrile seizures. Emerg Med Clin North Am 1987; 5: 719-37.

9 Millichap JG, Colliver JA. Management of febrile seizures: survey of current practice and phenobarbital usage. Pediatr Neurol 1991; 7: 243-8.

10 Joint Working Group of the Research Unit of the Royal College of Physicians and the British Paediatric Association. Guidelines for the management of convulAssociation. Guidelines for the manageme
sions with fever. $B M 7$ 1991; 303: 634-6.

11 Falconer MA, Serafetinides MD, Corsellis JA. Etiology and pathogenesis of temporal lobe epilepsy. Arch Neurol 1964; 10: $233-48$.

12 Kuks JBM, Cook MJ, Fish DR, et al. Hippocampal sclerosis in epilepsy and childhood febrile seizures. Lancet 1993; 342: $1391-4$

13 Nelson KB, Ellenberg JH. Predictors of epilepsy in children who have experienced febrile seizures. N Engl F Med 1976; 295: $1029-33$.
14 Annegers JF, Hauser WA, Shirts SB, et al. Factors prognostic of unprovoked seizures after febrile convulsions. $N$ Engl f Med 1987; 316: 493-8.

15 Verity CM, Butler NR, Golding J. Febrile convulsions in a national cohort followed up from birth. I - Prevalence and recurrence in the first five years of life. $B M Y 1$ 1985; 290: 1307-10.

16 Wallace SJ. The child with febrile seizures. London: Wright, 1988.

17 Stores G. When does an EEG contribute to the management of febrile seizures? Arch Dis Child 1991; 66: agement.

18 Hirtz DG, Nelson KB. The natural history of febrile seizures. Ann Rev Med 1983; 34: 453-71.

19 Holmes GL. How to evaluate the patient after a first seizure. Postgrad Med 1988; 83: 199-209.

20 Hopkins A, Garman A, Clarke C. The first seizure in adult life: value of clinical features, electroencephalography, and computerised tomographic scanning in prediction of seizure recurrence. Lancet 1988; i: 721-6.

21 van Donselaar CA, Geerts AT, Schimsheimer R-J. Idiopathic first seizure in adult life: who should be treated? $B M \mp$ 1991; 302: 620-3.

22 Russo LS, Goldstein KH. The diagnostic assessment of single seizures. Is cranial computed tomography necessary? Arch Neurol 1983; 40: 744-6.

23 Goodin DS, Aminoff MJ. Does the interictal EEG have a role in the diagnosis of epilepsy? Lancet 1984; i: 837-9.

24 Stores G. Clinical and EEG evaluation of seizures and seizure-like disorders. $\mathfrak{f}$ Am Acad Child Psychiatry 1985; 24: $10-6$.

25 Mizrahi EM. Medical progress. Electroencephalographic/ polygraphic/video monitoring in childhood epilepsy.

26 Binnie CD, Channon S, Marston D. Learning disabilities in epilepsy: neurophysiological aspects. Epilepsia 1990; 31 (suppl 4): S2-8.

27 Stores G. Electroencephalographic parameters in assessing the cognitive function of children with epilepsy. Epilepsia 1990; 31 (suppl 4): S45-9.

28 Bachman DS, Hodges FJ, Freeman JM. Computerized axial tomography in chronic seizure disorders of childhood. Pediatrics 1976; 58: 828-32.

29 Duncan R, Patterson J, Hadley DM, et al. CT, MR and SPECT imaging in temporal lobe epilepsy. 7 Neurol Neurosurg Psychiatry 1990; 53: 11-5.

30 Theodore WH, Katz D, Kufta C, et al. Pathology of temporal lobe foci: correlation with $\mathrm{CT}, \mathrm{MRI}$ and PET. Neurology 1990; 40: 797-803.

31 Chugani HT. The use of positron emission tomography in the clinical assessment of epilepsy. Semin Nucl Med 1992; 12: 247-53.

32 Chugani HT. Functional brain imaging in pediatrics. Pediatr Clin North Am 1992; 39: 777-99.

33 Sankar R, Chugani HT. Strategies for diagnosis and treatment of childhood epilepsy. Curr Opin Neurol Neurosurg 1993; 6: 398-402.

34 O'Tuama LA, Urion DK, Janicek MJ, et al. Regional cerebral perfusion in Landau-Kleffner syndrome and related childhood aphasias. F Nucl Med 1992; 33: 1758-65. 